\title{
SUPPRESSED NITROGEN EVOLUTION FROM COAL-DERIVED SOOT AND LOW-VOLATILITY COAL CHARS
}

\author{
JOHN C CHEN ANIS STEPHEN NIKSA
}

\begin{abstract}
This laboratory study uses a novel furnace to resolve nitrogen evolution during the three stages of pulverized coal combustion. primary devolatilization, secondary pyrolysis, and combustion The behavior of six coals depicts continuous rank variations, as well as suppressed nitrogen evolution from low volatility coals. During primary devolatilization of any coal, aromatic compounds in tar and oils are virtually the only shuttles for nitrogen out of the coal matrix. The small amounts of $\mathrm{HCN}$ observed while primary devolatilization winds down probably come from the char, because char particles are significantly hotter than tar in these experiments. Secondary pyrolysis promotes additional $\mathrm{HCN}$ evolution from both char and tar Moreover, substantial fractions of the volatile-nitrogen from primary devolatilization is reincorporated into a carbonaceous soot matrix for all coal types The fraction of coal nitrogen incorporated into soot remains constant, even while soot yields dramatically increase.

Incorporation of nitrogen into soot has the potential to substantially reduce the amount of coal nitrogen amenable to aerodynamic NO, abatement strategies for coals with large tar yields. This potential limitation is compounded by another limitation for low volatility coals. Whereas one-half to two-thirds of the coal-nitrogen is expelled by thermal decomposition from other coal types, only 30 to $40 \%$ is expelled from low volatility samples This tendency suggests that nitrogen functionalities become much more refractory as their surrounding aromatic domains become more extensive, either in high rank coals or soot. For such systems, our measurements indicate that the only way to expel the nitrogen is to burn it away
\end{abstract}

\section{Introduction}

During pulverized fuel firing in utility boilers, coal nitrogen is expelled in three stages. Initially during primary devolatilization, fuel nitrogen is liberated as a structural element in heavy, aromatic compounds collectively called tar. 'Next, the volatiles in hot fuel-rich gases undergo secondary pyrolysis and oxidative pyrolysis, which converts tarnitrogen into HCN. ${ }^{2}$ Since tar is the main shuttle for fuel nitrogen and has a strong propensity to soot, nitrogen in tar is also incorporated into another carbonaceous matrix during secondary pyrolysis. ${ }^{3}$ Additional fuel nitrogen is expelled from the char as $\mathrm{HCN}$ during the second stage on time scales which are considerably longer than those for primary devolatilization. Eventually in the third stage oxygen contacts the char, liberating additional nitrogen either by direct chemical conversion to $\mathrm{NO}$ or by thermal dissociations induced by the higher particle temperatures associated with char combustion.

Our radimt coal flow experiment ${ }^{3-5}$ maintains the conditions needed to clearly resolve these stages while it imparts heat fluxes, heating rates, temper- atures, and reaction times like those in pulverized coal flames. This study extends the characterization of fuel nitrogen evolution in our previous studies of primary and secondary pyrolysis in two respects First, data is reported for several low volatility samples throughout primary and secondary pyrolysis, to better understand why they are so resistant to aerodynamic $\mathrm{NO}_{x}$ abatement strategies. Second, studies with oxygen relate carbon bumout and nitrogen evolution during the latest stages, and gauge the extent that nitrogen incorporated into soot and char can be driven off by raising temperatures for diverse coal samples

\section{Experimental}

This brief description is supported by additional details ${ }^{-1}$ and design specifications ${ }^{6}$ in other publications. A schematic of the radiant coal flow reactor appears in Fig. 1. At the top a feeder dumps pulverized particles into an entrainment stream, forming an optically-thin suspension which flows downward into a radiant furnace section. The radiant 


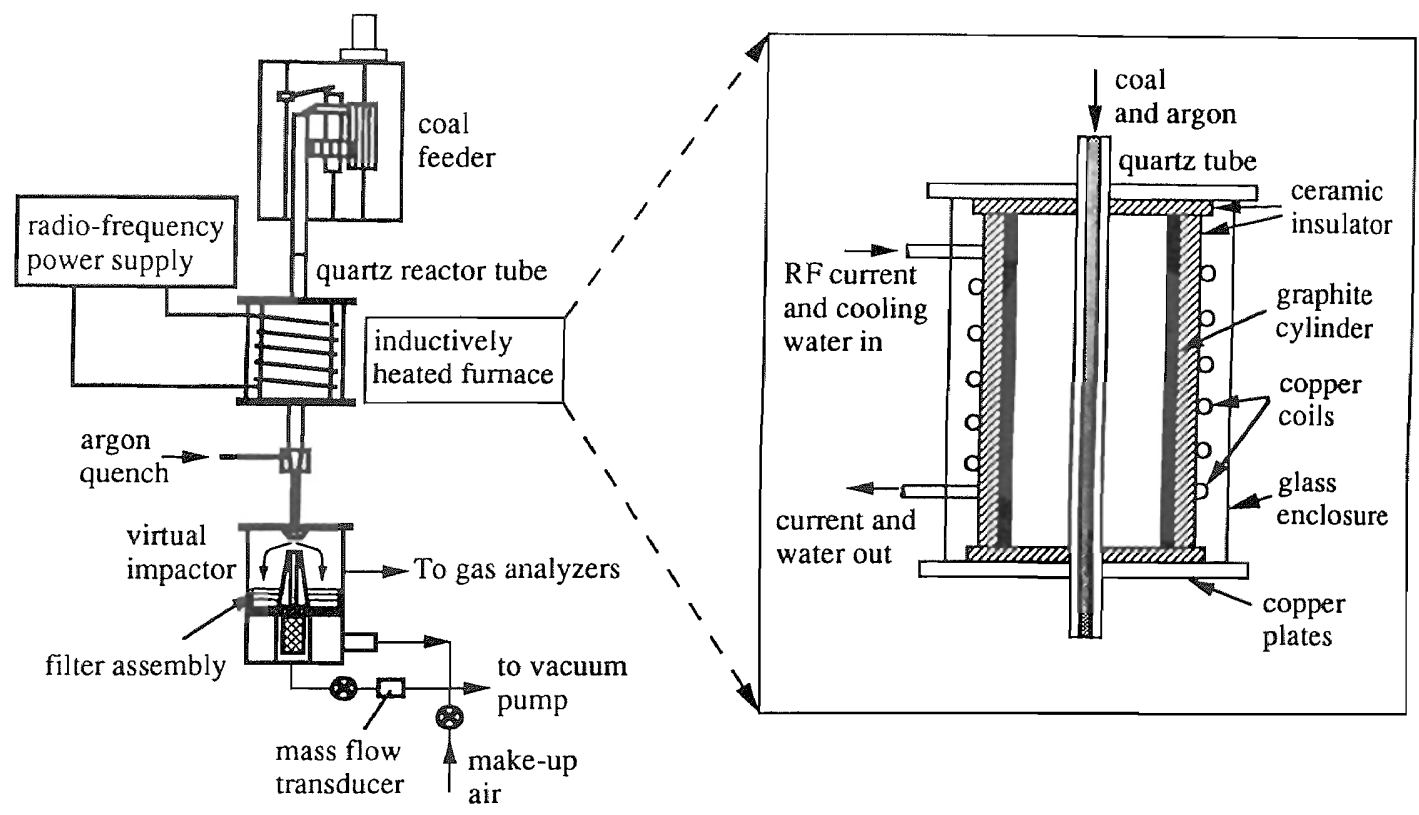

FIc. 1. The radiant coal flow reactor

section consists of a quartz tube on the axis of a graphite cylinder which is inductively-heated to temperatures to $1850 \mathrm{~K}$. Near-black-body thermal emission from the graphite rapidly heats the particles as they traverse the furnace. Since the entrainment gas is transparent to the radiation its only means of heating is by convection from the tube wall and particles. Dilute suspensions, which are used in the primary pyrolysis studies, have little interfacial surface area for interphase heat transfer, so the entrainment gas remains relatively cool and quenches chemistry among primary products as they are expelled. To promote secondary reactions of the volatiles, the suspension loading is increased to enhance interphase heat transfer and raise the gas temperature. In addition, residence times are extended for secondary chemistry studies by using a similar furnace whose hot zone is two-and-one-half times longer than that for the primary pyrolysis studies.

Adding oxygen to the process stream achieves higher particle temperatures for the same nominal operating condition because of the combustion exotherm. Residence times are extended by extending the flow tube by $30 \mathrm{~cm}$ beyond the exit of the longer radiant section. Oxygen is blended in the entrainment streams to the desired level upstream of the furnace section.

For primary pyrolysis studies, residence times are varied at a fixed furnace temperature $(1840 \mathrm{~K})$. Gas velocities and coal feed rates are simultaneously adjusted to vary residence time but fix the suspension loading at 300 particles $/ \mathrm{cm}^{3}$ at the inlet. As seen in the calculated temperature profiles for primary pyrolysis studies in Fig. 2a, thermal histories in a series of runs have nearly the same heating rate. but the suspension achieves different temperatures at the outlet in each ciase. Particles begin heatng $1 \mathrm{~cm}$ upstream of the inlet plane, due to the radiation escaping through the flow tube. Inside the furnace at $1840 \mathrm{~K}$ the radiant flux onto the centerline is $60 \mathrm{~W} / \mathrm{cm}^{2}$, similar to the 50 to $100 \mathrm{~W} / \mathrm{cm}^{2}$ estimated for coal-fired burners in utility boilers. Even though their heating rate exceeds $10^{4} \mathrm{~K} / \mathrm{s}$, particles are always much cooler than the wall temperature at the outlet. Most importantly, the gas heats at only $2300 \mathrm{~K} / \mathrm{s}$, and reaches only $600 \mathrm{~K}$ at the outlet. At this temperature, secondary reactions are too slow to affect coal-derived products, as demonstrated elsewhere ${ }^{5,6}$

For secondary pyrolysis studies, the severity of the thermal processing is regulated simply by increasing the furnace temperature in successive runs with the same inlet gas velocity and suspension loading (1200 particles $/ \mathrm{cm}^{3}$ ). The thermal histories for these cases appear in Fig. 2b. The suspension initially heats faster than the gas, but the high convective heat transfer rate quickly balances the particle and gas heating rates at nominal values of 5 $\times 10^{3} \mathrm{~K} / \mathrm{s}$. As a result, the temperature difference is less than $1.50 \mathrm{~K}$ and the gas temperature reaches $1150 \mathrm{~K}$ at the outlet of the furnace at $1740 \mathrm{~K}$. The most severe condition for primary pyrolysis of 90 $\mathrm{ms}$ in an $1840 \mathrm{~K}$ furnace imparts a maximum tem- 

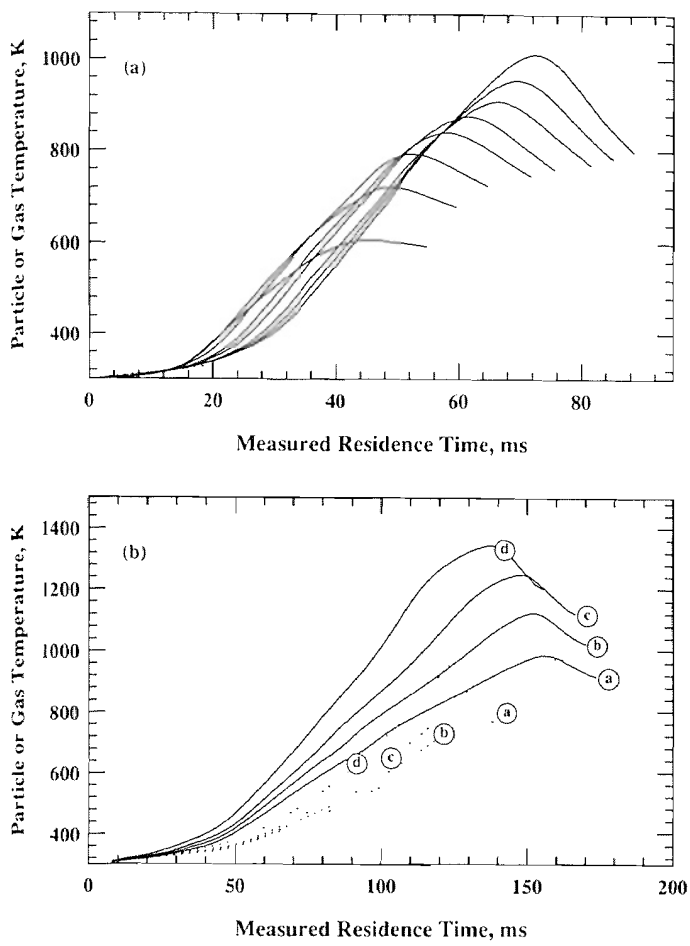

Fic. 2. (a) Calculated thermal histories of the suspensions (solid curves) for measured values of residence time in the primary devolatilization studies of $56,61,66,72,77,83,87$, and $90 \mathrm{~ms}$, and calculated gas temperature for $90 \mathrm{~ms}$ (dotted curve). (b) Cakulated thermal histories of particles (solid curves) and gas (dotted curves) for secondary pyrolysis with 1200 particles $/ \mathrm{cm}^{3}$ entrained at $18 \mathrm{~cm} /$ $s$ at the inlet. The letters denote fumace temperatures and measured residence times as follows: $a$ $=1480 \mathrm{~K}, 174 \mathrm{~ms}, b=1570 \mathrm{~K}, 170 \mathrm{~ms} ; c=1660$ $\mathrm{K}, 167 \mathrm{~ms}$, and $d=1740 \mathrm{~K}, 156 \mathrm{~ms}$.

perature of $1000 \mathrm{~K}$, which is similar to the $980 \mathrm{~K}$ achieved with the least severe secondary pyrolysis condition of $175 \mathrm{~ms}$ through the furnace at $1480 \mathrm{~K}$, in Fig. 2b.

Product recovery and analysis begin at the furnace outlet, where an argon quench stream rapidly quenches all chemistry and nucleates tar into an aerosol. About 2-4 wt.\% of aerosol deposits in the quench nozzle, regardless of the aerosol yield, ${ }^{4,6}$ so 2 wt. \% is added to all aerosol yields greater than 4 wt.\%. Products are segregated into bulk solid particles, tar/soot aerosol, and noncondensible gases with virtual impaction in an aerodynamic classifier, described elsewhere. ${ }^{4.6}$ All tar and char is collected on filters so that yields are determined gravimetrically. Pure tar samples for subsequent chemical analyses are prepared by extraction with tetrahydrofuran (THF) in an ultrasonic bath, followed by filtration through a 0.2 micron Teflon membrane. The membrane residue is weighed and denoted as the soot yield.

Noncondensible gases are quantified by non-dispersive infrared (NDIR) and chemiluminescence analyzers and gas chromatography Carbon, hydrogen, and nitrogen contents of condensed products are determined in-house. Mass and elemental balances are closed to within $5 \%$ in individual runs, so that subsequent interpretations are not subject to inordinate scatter in the data.

The six coals in this study were distributed by the Pittsburgh Energy Technology Center (PETC), except for the Colorado Basin, Lower Hartshorne, and Pocahontas No. 3 low volatility samples, which were obtained from the Penn State Coal Bank. As seen in Table $I$, their ranks range from subbituminous B to low-volatile bituminous. The samples were aerodynamically classified by PETC into the 75-106 $\mathrm{\mu m}$ size grade (except for the coals from Penn State, which were sized in-house), dried in a vacuum oven for at least 12 hours at $25 \mathrm{in}-\mathrm{Hg}(\mathrm{vac})$ and $60^{\circ} \mathrm{C}$, and stored under argon. Measured weight loss and yields were converted to the dry, ash-free (daf) basis using the ash levels in Table I.

\section{Results}

\section{Primary Devolatilization.}

Transient weight loss and tar yields during primary devolatilization for the Dietz subbituminous and Pit. \#8 coals appear in Fig. 3. They indicate clearly that the relative contribution of tar to the initial weight loss is rank dependent. The Dietz expels significant amounts of gases from the onset of devolatilization, whereas initially the gas yields from the Pit. \#8 are too low to resolve on this scale. Tar evolution from all coals ceases well before weight loss reaches asymptotic values. For the Dietz, the rate of weight loss actually increases while tar yields remain at the ultimate value. As shown elsewhere, ${ }^{5,6} \mathrm{CO}$ and $\mathrm{H}_{2} \mathrm{O}$ evolution account for most of the additional weight loss during the final stages, so the increase in rate of weight loss in the later stage for the Dietz is consistent with its higher oxygen content.

Nitrogen distributions during primary devolatilization from the Dietz and Pit. \#8 appear in Fig. 4; ultimate values for the other coals appear in Table Il. Condensed liquid hydrocarbons are virtually the only shuttles for fuel nitrogen during primary devolatilization, NO never contains more than fractions of a percent of the fuel- $N$, and $\mathrm{HCN}$ contains $10 \%$, at most. Actually, most of the HCN in Figs. ta and $b$ may be directly expelled from the char, because nitrogen functional groups are the same in char and tar, and the char particles are significantly 
TABLE I

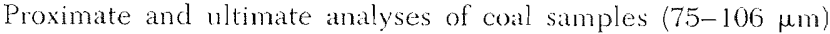

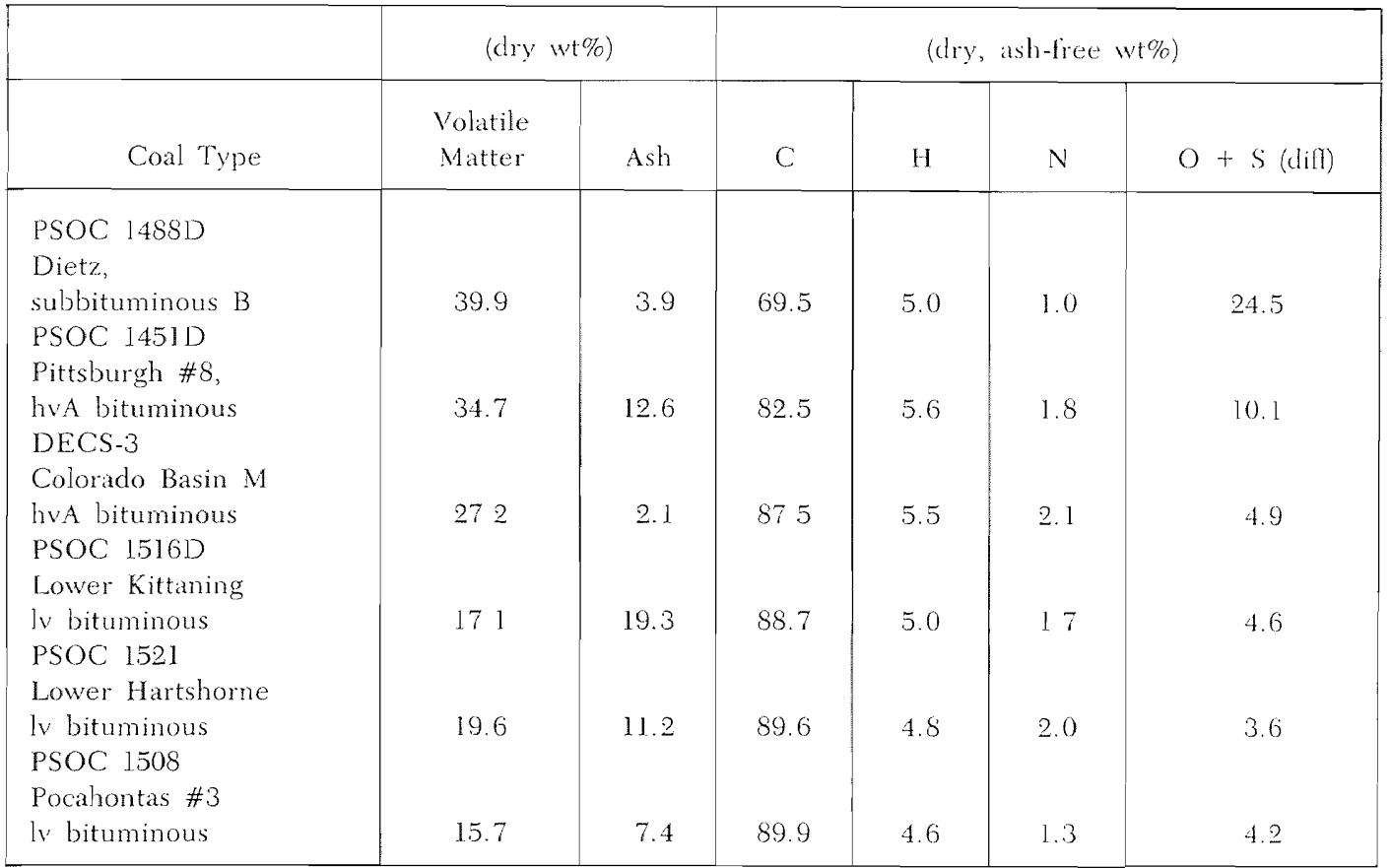

hotter than the tars in the entrainment stream in these experiments.

The breach of closure in the nitrogen balance for the Dietz becomes significant for the longest residence times, suggesting that significant amounts of additional nitrogenous species, probably ammonias, may be evolved from low rank coals. This tendency appears in the data from the other coals in Table II, but to a much lesser extent, if at all.

\section{Secondary Pyrolysis:}

Total weight loss, the combined yields of tar, oils, and soot, and the soot percentage among these three products appear in Fig. 5 for the Dietz and Pit. \#8 coals. Weight loss reaches its ultimate values of 57 wt. \% and 61 wt.\% daf for the Dietz and the Pit. \#8, respectively, for furnace temperatures above $1550 \mathrm{~K}$. These values are comparable to respective values of $53 \%$ and $58 \%$ obtained at the longest residence time for primary devolatilization (Fig. 3).

The yields of tar/oils plus soot remain the same throughout secondary pyrolysis, within an experimental uncertainty of \pm 2 wt. \%. For both coals, the invariant values are identical to the yields of tar/ oils at the longest residence time for primary devolatilization, which are $22 \%$ for the Dietz and $36 \%$ for the Pit. \#8. As seems intuitively obvious, these yields would be invariant if tars are the precursors to soot. However, by virtue of their different ele- mental compositions, tar and soot cannot possibly be exchanging quantitatively at all stages of secondary pyrolysis, as demonstrated elsewhere ${ }^{3}$ While aggregate yields remain the same, the soot percentage among oils and aerosol covers a wide range as fumace temperatures are increased from 1480 to $1740 \mathrm{~K}$, growing from 18 to $70 \%$ for the Dietz and from 30 to $86 \%$ for the Pit. \#8. Note also that the soot percentage is near-linearly proportional to furnace temperature, so furnace temperature becomes a convenient scale for the severity of secondary reactions in the following results.

In Fig. 6 cumulative fractional distributions among major nitrogen species resolve coal nitrogen into $\mathrm{NO}$, tar/oils, soot, HCN, and char HCN becomes the major repository for fuel nitrogen, increasing from $6 \%$ to $40-48 \%$ as most of the tar is converted into soot. The initial value is the same as for the longest residence time for primary devolatilization of these coals. The residual nitrogen in char decreases from $60 \%$ to respective values of 50 and $40 \%$ for the Dietz and Pit. \#8 throughout secondary pyrolysis. But direct evolution from char accounts for no more than half of the additional HCN for both coals. The other half comes from tar. The fraction of coal-nitrogen in tar decreases for two reasons. First, there is less tar in the system as soot becomes more abundant (cf. Fig. 5) and, second, tar compounds independently expel their nitrogen as HCN during secondary pyrolysis. Only the second factor is consistent 


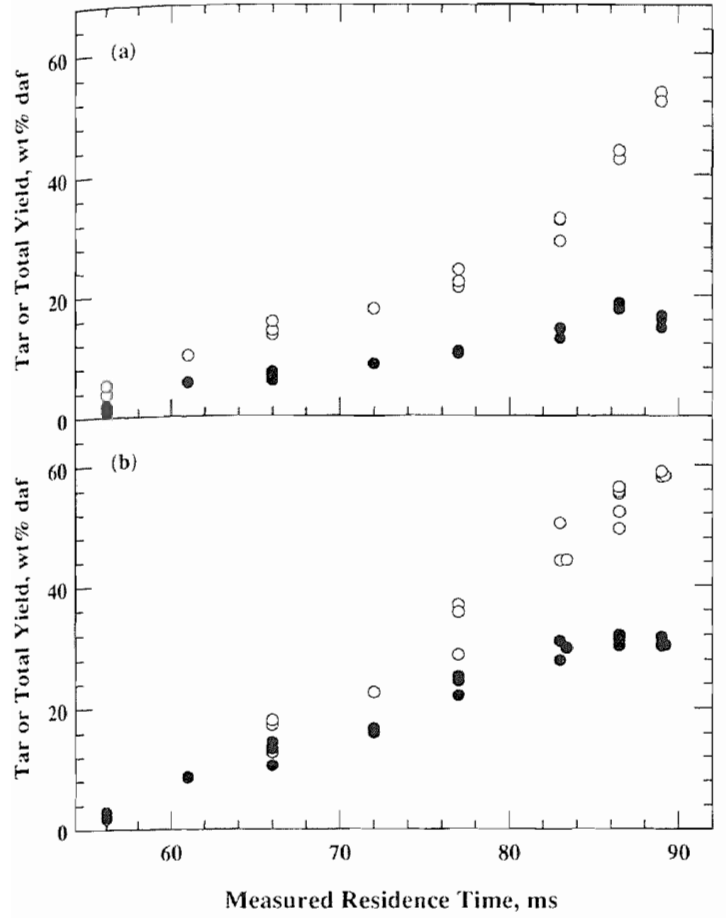

FIC. 3. Transient weight loss $(O)$ and tar yields - versus measured residence times from the furnace at $1840 \mathrm{~K}$ for (a) Dietz and (b) Pit. \#8.

with variations in the atomic $\mathrm{C} / \mathrm{N}$ ratio of tar, which increase from 95 to 170 for the Dietz and from 63 to 86 for the Pit. \#8 during secondary pyrolysis. $\mathrm{HCN}$ production during tar conversion is also consistent with the abundance of cyano aromatics during secondary tar pyrolysis at high temperatures reported by Nelson et al. ${ }^{7}$

Results in Fig. 6 also show that substantial fractions of coal nitrogen are incorporated into soot. Clearly, tar can be converted into soot with significant numbers of its nitrogen functionalities intact. With the Pit. \#8, a quarter of the coal nitrogen expelled during primary devolatilization is reincorporated into a carbonaceous solid during sooting. With the Dietz, $10 \%$ of the volatile- $\mathrm{N}$ is in the soot, consistent with its lower yields of tar and soot. The total amount of coal-nitrogen in soot remains constant throughout secondary pyrolysis, even while soot yields increase dramatically. Consequently, the fractional nitrogen contents of soot decrease throughout secondary pyrolysis.

Since NO is never present in significant amounts, HCN, char, tar/oils, and soot account for almost all of the coal-nitrogen. Closure of the nitrogen balance does improve for both coals with increasing furnace temperature. However, particularly for the Dietz, the balance is breached by $10-15 \%$ during the initial stages, as noted for the end of primary

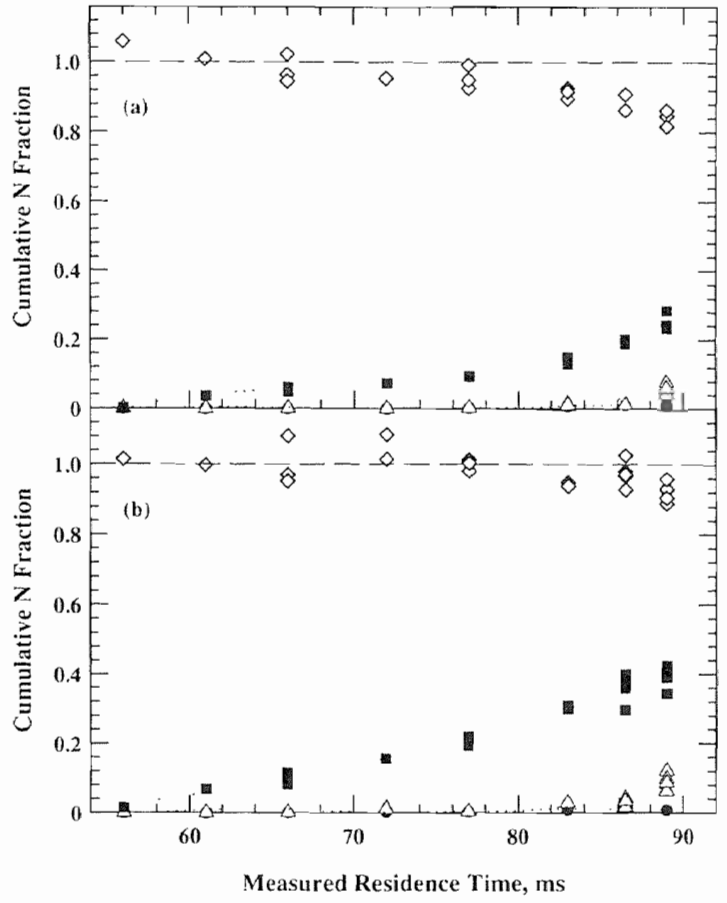

F1G. 4. (a) Cumulative transient nitrogen fractions from Dietz coal versus measured residence times in the furnace at $1840 \mathrm{~K}$ as $\mathrm{NO}(-), \mathrm{HCN}(\triangle)$ tar plus oils (1), and char $(\diamond)$. (b) Cumulative transient nitrogen fractions from Pit. \#8 versus measured residence times in the fumace at $1840 \mathrm{~K}$ as NO (O),

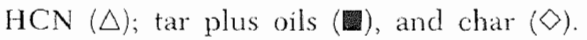

devolatilization (see Fig. 4). Since the balance eventually closes the missing nitrogen species must be relatively unstable, which rules out molecular nitrogen and points to ammonia.

The nitrogen distribution for a representative $l v$ bituminous coal is presented in Fig. 7. Our previous description of the behavior of weight loss, tar/ oils plus soot, and soot conversion for the lower rank coals applies to the $\mathrm{l} v$ bituminous samples as well, except that much less of the coal nitrogen is expelled from the char during secondary pyrolysis. Total nitrogen release increases only from $28 \%$ to $38 \%$. As with the Pit. \#8, about one-fourth of the volatile-nitrogen from the lv bituminous is incorporated into soot, and most of the remainder eventually appears as HCN. However, the nitrogen balance is breached by 10\% at even the highest temperatures. Ammonia would not be expelled from such a high rank coal, so we are developing diagnostics for $\mathrm{N}_{2}$ and $\mathrm{C}_{2} \mathrm{~N}_{2}$ to resolve this issue.

\section{Combustion Studies.}

Adding oxygen to the process stream has two important consequences. (1) Higher particle temper- 
TABILE II

Ultimate weight loss, tar yields, and nitrogen distributions for primary devolatilization.

\begin{tabular}{|l|c|c|c|c|c|}
\hline & $\begin{array}{c}\text { Weight Loss } \\
\text { Coal }\end{array}$ & $\begin{array}{c}\text { Tar Yield } \\
\text { (daf wt \%) }\end{array}$ & $\begin{array}{c}\% \mathrm{~N} \\
\text { release }\end{array}$ & $\begin{array}{c}\% \text { N } \\
\text { in tar }\end{array}$ & $\begin{array}{c}\text { N } \\
\text { in HCN }\end{array}$ \\
\hline PSOC 1488D & 53.0 & 22.0 & 40.9 & 19.7 & 5.7 \\
PSOC 1451D & 58.0 & 32.0 & 48.1 & 30.8 & 9.7 \\
DECS-3 & 35.7 & 29.7 & 30.9 & 25.6 & 0.7 \\
PSOC 1516D & 31.4 & 19.9 & 30.1 & 21.2 & 5.4 \\
PSOC 1521 & 30.3 & 26.7 & 27.3 & 24.2 & 0. \\
PSOC 1508 & 22.4 & 18.8 & 21.4 & 18.4 & 0. \\
\hline
\end{tabular}

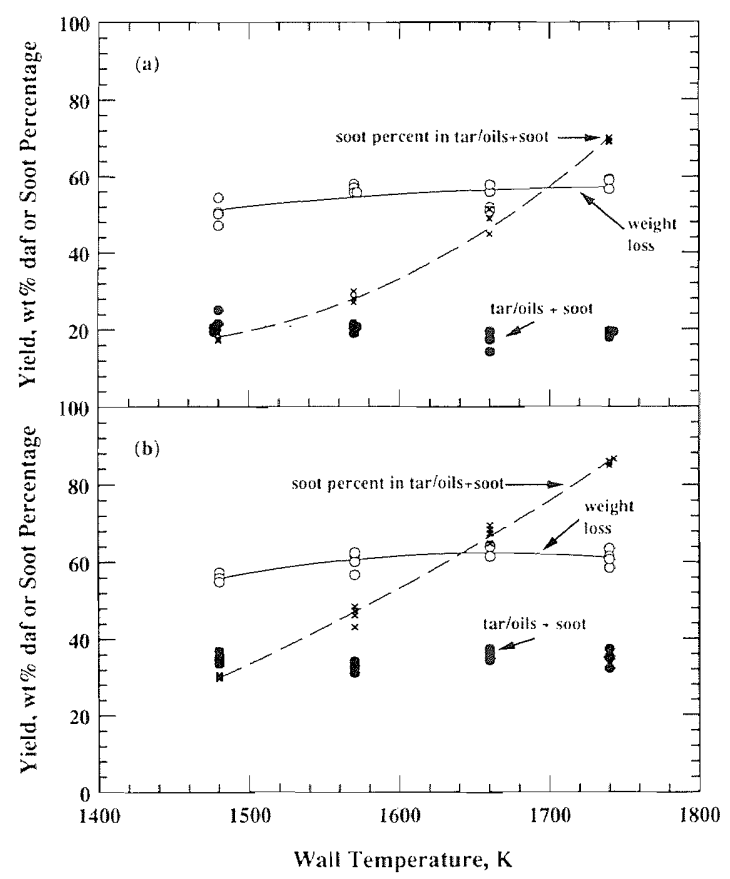

$F_{1 C}$ 5. Weight loss $(\mathrm{O})$, aggregate yields of tar plus oils plus soot (O), and soot percentage in the aggregate ( $X$ and dashed curve) versus furnace temperature for (a) Dietz and (b) Pit. \#8.

atures are achieved for the same nominal operating conditions because of the combustion exotherm, and (2) all volatiles, soot, and some of the chars are oxidized into the most stable combustion products. The first consequence might promote more extensive fuel-nitrogen release simply by enhancing thermal decomposition. However, the low and near-asymptotic levels of total nitrogen release for the most severe secondary pyrolysis conditions make this an unlikely prospect (albeit the desirable one). Direct oxidation of char nitrogen is promoted by the second consequence. Its impact is best seen by comparing the

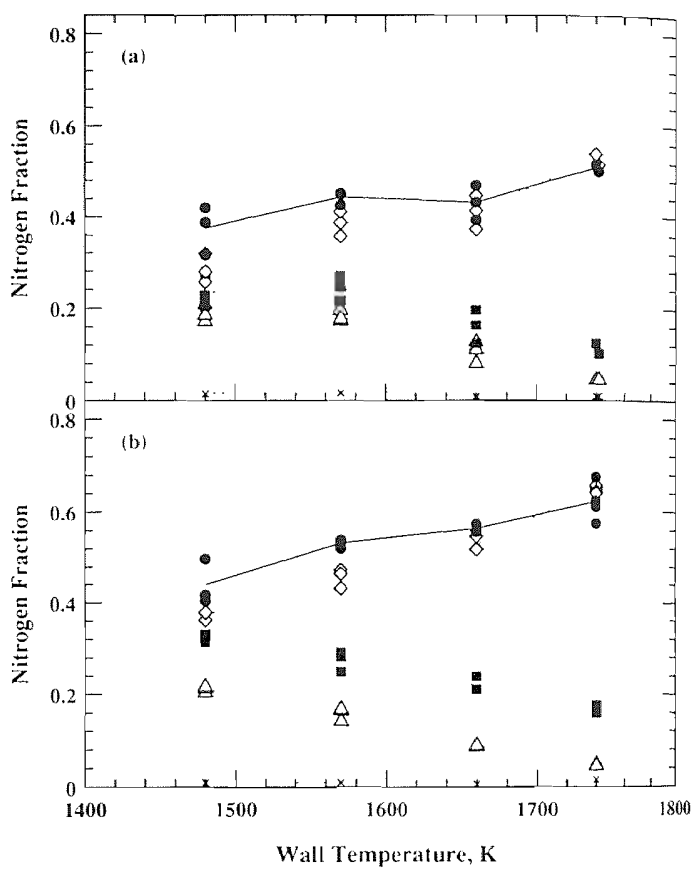

Fla 6. (a) Cumulative nitrogen fractions from Dietz during secondary pyrolysis as NO $(X)$; tar plus oils $(\triangle)$; soot $(-$ ) HCN $(\diamond)$; and char $(\bullet)$. Values for char are referenced to the top of the scale, so closure of the nitrogen balance is indicated by the convergence of the lines for $\mathrm{HCN}$ and char. (b) $\mathrm{Cu}$ mulative nitrogen fractions from Pit \#8 during secondary pyrolysis as NO $(X)$, tar plus oils $(\triangle)$; soot $(\square), H C N(\diamond)$; and char $(\theta)$ Values for char are referenced to the top of the scale, so closure of the nitrogen balance is indicated by the convergence of the lines for HCN and char.

extents of carbon burnout and nitrogen evolution.

The results in Fig. 8 convey the correlation between nitrogen and carbon burnout for all four low volatility samples. Different extents of burn-out were 


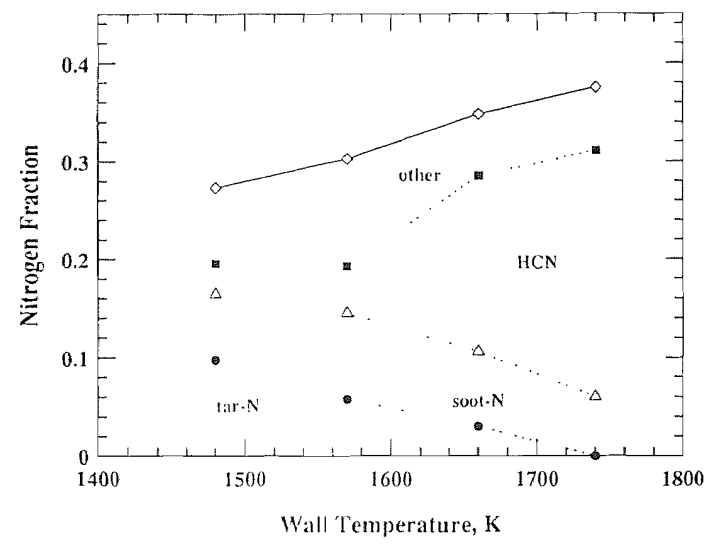

FIG. 7 Cumulative nitrogen fractions from Lower Kittaning lv bituminous coal during secondary pyrolysis as tar plus oils ( soot $(\triangle)$; $\mathrm{HCN}$ ( and char $(\diamond)$. Values for char are referenced to the top of the scale, so closure of the nitrogen balance is indicated by the convergence of the lines for HCN and char.

achieved by increasing oxygen levels from 14 to $40 \%$, corresponding to nominal equivalence ratios from 0.5 to 1.5 . For all coals, preferential nitrogen (vs. carbon) evolution during primary devolatilization is compensated for by faster carbon conversion during combustion. Consequently, it is not possible to expel nitrogen from these chars by themal processing alone. The only way to completely expel nitrogen from these chars is to burn it away. Of course, there is signjlicant conversion of fuel-N into NO during combustion, and the ultimate amounts of NO for these four samples approaches

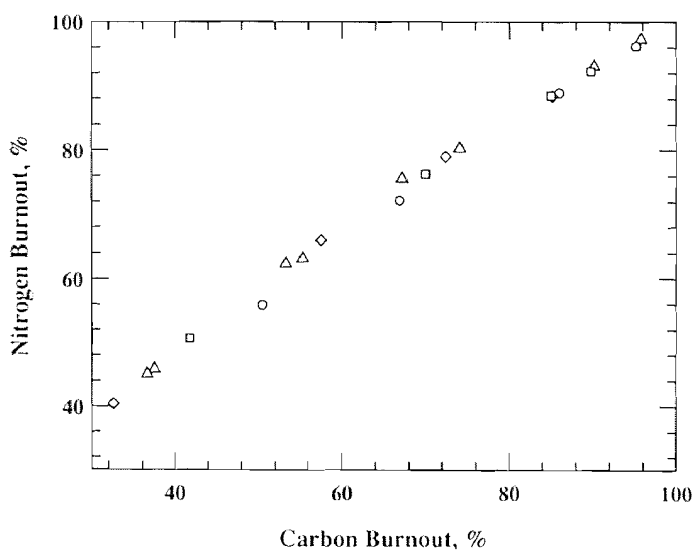

FIC, 8. Correlation between fractional nitrogen and carbon burnout for DECS-3 $(O) ; 1516 \mathrm{D}(\Delta)$; $1521(\square)$; and $1508(\diamond)$ coals. or attains asymptotic values of roughly $35 \%$ of the fuel nitrogen.

\section{Discussion}

The evolution of coal nitrogen during the earliest stages of combustion involves very few species, and shows the same tendencies for al] coal types. During primary devolatilization, the extents of nitrogen evolution are roughly proportional to the mass-based yields of tar and oils. In fact, tar and oils are virtually the only shuttles for nitrogen out of the coal matrix, especially during the early stages. The predominance of $\operatorname{tar}-N$ is entirely consistent with recent characterizations of nitrogen functionalities in bituminous coals as exclusively pyrrolic and pyridinic. ${ }^{8,9}$ Being incorporated into the aromatic nuclei, these functionalities are relatively more stable than bridges among nuclei. They are released intact, as components of tar molecules, provided that secondary reactions are eliminated. Rings do rupture to form $\mathrm{HCN}$ at temperatures above $1000 \mathrm{~K}$ and residence times of longer than 1 sec, ${ }^{2,10}$ but such conditions are much more severe than in this reactor, so no $\mathrm{HCN}$ was ever observed while tars were being expelled.

Extensive secondary chemistry affects the nitrogen distributions by promoting HCN evolution, presumably due to heteroatomic ring rupture in both char and tar. Furthermore, the higher particle temperatures achieved under these conditions increases the amount of nitrogen released from the char, but only by an additional 10-15\%. Thermal decomposition alone cannot completely expel the coal nitrogen under typical p.f. firing conditions.

The immediate incorporation of nitrogen into soot traces the importance of direct tar conversion during the initial stages of soot fomation. We also observed that the fraction of coal nitrogen incorporated into soot remains constant, even while soot vields dramatically increase. This suggests that soot mass grows by the addition of species which are devoid of nitrogen. Mass growth via addition of light hydrocarbons would satisfy this implication, as do consecutive reactions of tar decomposition to light hydrocarbons with subsequent addition to soot, provided that decomposing tars expel their nitrogen before adding to the soot. Direct tar addition to soot in the later stage is plausible only if tars eliminate their nitrogen before adding to the soot.

Aside from these mechanistic implications, incorporation of nitrogen into soot is an heretofore unrecognized aspect of nitrogen evolution during the initial stages of pulverized-coal combustion. It has the potential to substantially reduce the amount of coal nitrogen amenable to aerodynamic NO. 
abatement strategies for coals with large tar yields. This potential limitation affects all coal types, and is compounded by another limitation for low volatility coals. Whereas one-half to two-thirds of the coal-nitrogen is expelled from both coals of lower rank during secondary pyrolysis, only 30 to $40 \%$ is expelled from low volatility samples. This tendency suggests that nitrogen functionalities become much more resistant to thermal decomposition as their surrounding aromatic domains become more extensive. This idea probably also explains why nitrogen in soot cannot be liberated by thermal processing alone. For extensive condensed-ring aromatic systems, the only way to expel nitrogen is to bum it away.

\section{Acknowledgement}

This research was sponsored by the Electric Power Research Institute (EPRI), under their Exploratory Research Program. The U.S Environmental Protection Agency adso provided support during the later stages We are also grateful to the Link Foundation for providing an Energy Fellowship to ] Chen during academic year 1988-89. Technical contributions are gratefully acknowledged to S Cho, and C.-W. Lau.

\section{REFERENCES}

1 Fremaut, J D., Zablelskt, M. F. And SeEry, D. J.: Nineteenth Symposium (International) on Combustion, p. 1159, The Combustion Institute, 1983.

2. Bruinsma, O. S L., Geertsma, R. S., Bank, P AND MOUliJn, ]. A. Fuel, 67, 334 (1988).

3. Chen, I. C., Castagnoli, C and Niksa, $S$. Energy and Fuels, 6, 264 (1992).

4. Chen, J C. AND Niksa, S. Rev Sci. Instr 63(3), 2073 (1992).

5. Chen, J. C AND Niks , S.: Energy and Fuels, $6,254(1992)$.

6. Chen, J. C. Effects of Secondary Reactions on Product Distribution and Nitrogen Evolution from Rapid Coal Pyrolysis, Ph.D thesis, Mechanical Engineering Department, Stanford University, Stanford, 1991

7. NELSON, P. F., KELLY, M. D. AND WORNAT, M J. Fuel, 70, 403 (1991).

8. Burchlle, P ANd WElch, L. S. Fuel, 68, 100 (1989).

9. Waliacle, S., BakTle, K. D AND PEkRY, D L. Fuel, 68, 1450 (1989)

10. Axworthir, A E., DaYan, $\mathrm{V}$. H AND MarTiN, G. B.. Fuel, 57, 29 (1978). 